\title{
GAYA KEPEMIMPINAN DAN MOTIVASI KERJA KARYAWAN BNI KANTOR CABANG UTAMA JPK, BANDUNG
}

\author{
Arif Partono Prasetio \\ Tieka Trikartika Gustyana \\ Muhammad Ishla Fakhri \\ Satria Jayasena
}

Fakultas Ekonomi dan Bisnis, Universitas Telkom

Email: partono67@gmail.com

Submitted: Jan 06, 2018; Reviewed: Jan 08, 2018; Accepted: Sept 05, 2018

\begin{abstract}
Motivating employee to work better in order to succeed in their job is important to ensure the success of the company. Organization can enhance the motivation by recognizing employee's hard work and provide an environment that meets their basic emotional drives to perform. The present study aimed to explore the leadership style on employee motivation in one of the main branch of public banking in Bandung. Data had been collected using questionnaire and distributed by nonprobability sampling techniques. The instrument employs 18 items on leadership style and 18 questions on motivation. The study found that the leadership style matched with employee expectation and employees were highly motivated. The results also showed that the degree of conformity between leadership styles has a significant influence on employee motivation. Organization should encourage their leader to continously implement style that drive the motivation in order to get the best result from the employee.
\end{abstract}

Keywords: Leadership Style, Path-Goal, Motivation, Regression Analysis

\section{PENDAHULUAN}

Tantangan yang dihadapi organisasi bisnis senantiasa meningkat. Tantangan ini dihadapi oleh setiap pelaku bisnis baik berskala kecil, menengah, maupun besar. Nama besar saja saat ini tidak cukup untuk menarik konsumen agar menggunakan jasa yang disediakan. Organisasi harus senantiasa menciptakan keunggulankeunggulan baru agar bisa memenangkan persaingan. Salah satu sumberdaya yang dapat dioptimalkan untuk menciptakan keunggulan bersaing adalah manusia (karyawan). Organisasi perlu mengembangkan karyawan yang berprestasi dan berkontribusi. Agar karyawan bisa berkontribusi optimal mereka memiliki motivasi untuk menjalankan pekerjaan sebaik mungkin. Motivasi kerja yang dimiliki karyawan merupakan aspek penting di tempat kerja. Karyawan yang termotivasi dapat meningkatkan produktivitas dan mencapai sasaran organisasi yang lebih tinggi. Barone (2016) menegaskan bahwa karyawan yang termotivasi akan terdorong untuk melakukan perubahan positif dalam hidup dan pekerjaannya. Hal tersebut diwujudkan dengan kinerja yang lebih baik, bekerja keras dan cerdas, bekerja lebih efektif, dan selalau berusaha memenuhi target atau deadline. Perilaku tersebut akan berdampak positif bagi organisasi secara keseluruhan. Hal senada dikemukakan oleh Anthony (2017) bahwa karyawan yang termotivasi akan menghasilkan karyawan yang efektif dalam menjalankan pekerjaan sehingga kinerja mereka akan lebih baik. Berbagai faktor dapat berpengaruh terhadap pembentukan motivasi kerja karyawan. Blasingame (2015) memaparkan tiga hal yang mempengaruhi motivasi karyawan; gaya manajemen, komunikasi, dan sikap profesionalisme. Naile dan Selesho (2015) menegaskan pentingnya unsur kepemimpinan dalam mendorong tumbuhnya hubungan berdasar rasa saling percaya, kreativitas, dan 
pengembangan terhadap tingkat motivasi karyawan. Sedangkan Daum (2015) melihat peran lain pemimpin dalam membangun motivasi karyawan melalui sikap dan perilaku integritas, peduli pada bawahan, memberi contoh bagaimana menjalankan pekerjaan, dan memberi solusi bagi masalah yang dihadapi. Penelitian di Pakistan oleh Akhtar dkk (2014) menemukan beberapa faktor yang mempengaruhi motivasi karyawan; penghargaan finansial, desain pekerjaan yang baik, pemenuhan gaji dan kebutuhan pribadi. Penelitian di Indonesia oleh Kusuma dkk (2015) menemukan bahwa kebijakan terkait pemberian insentif dapat mempengaruhi motivasi kerja karyawan. Selanjutnya, Prakoso dkk (2014) memaparkan faktor lain yang bisa mempengaruhi motivasi karyawan yaitu lingkungan kerja yang baik. Penelitian di Nigeria memperlihatkan keragaman faktor yang mempengaruhi motivasi kerja diantaranya; gaji dan kondisi pelayanan yang baik, promosi jabatan, pengakuan dan pemberian umpan balik, tingkat keamanan kerja, peluang untuk pengembangan profesional, pemberdayaan dan pemberian wewenang yang memadai, lingkungan kerja yang baik, pekerjaan yang memberikan tantangan dan bervariasi, tingkat partisipasi dalam pengambilan keputusan dapat meningkatkan motivasi kerja karyawan Osakwe (2014). Penelitian menggunakan responden dari industri perbankan di Pakistan oleh Khan dkk (2017) menyatakan bahwa faktor utama pembentuk motivasi karyawan adalah pemberian kewenangan untuk mengambil keputusan. Meski demikian, faktor lain seperti lingkungan kerja, pengakuan, dan potensi pengembangan diri juga dinilai penting. Penelitian dengan responden dari badan usaha milik negara di Jawa Barat dan Banten menemukan pengaruh faktor kompensasi terhadap motivasi kerja (Wulansari dkk, 2014). Penelitian ini menganalisis pengaruh gaya kepemimpinan yang diterapkan di salah satu kantor cabang bank milik pemerintah di Bandung terhadap tingkat motivasi kerja karyawannya. Peran pemimpin dalam membangun motivasi kerja merupakan faktor penting. Berbagai cara bisa dilakukan pemimpin untuk meningkatkan motivasi kerja karyawannya (Daum, 2015; Zwelling, 2012). Pimpinan cabang di industri perbankan menghadapi tantangan dan persaingan. Menjaga kualitas layanan, memperoleh target nasabah, target penyaluran kredit, dan menjaga keseimbangan kinerja keuangan cabangnya. Pilcher (2017) dan Skinner (2017) menekankan pentingnya unsur 2 pemimpin di perbankan. Mereka mengatakan tantangan terbesar yang dihadapi perbankan saat ini adalah kepemimpinan. Gaya kepemimpinan yang tepat akan memudahkan perbankan dalam menerapkan perubahan untuk menghadapi tantangan di masa depan. Gaya kepemimpinan berhubungan erat dengan motivasi. Kemampuan pemimpin untuk menggerakkan tim kerjanya agar mencapai tujuan ditentukan dengan penerapan gaya kepemimpinannya. Keselarasaan gaya kepemimpinan yang diterapkan dan penerimaan dari karyawan akan memudahkan pemimpin dalam memotivasi karyawan agar bekerja lebih baik dan efektif.

\section{KAJIAN LITERATUR DAN HIPOTESIS Gaya Kepemimpinan}

Kepemimpinan merupakan fenomena menarik terkait pengelolaan organisasi. Terdapat banyak faktor yang terlibat diantaranya kondisi, lingkungan, kepribadian, dan hubungan (DeCaro, 2005). Banyak definisi kepemimpinan yang disajikan oleh para ahli. Daft (2014) menjelaskan gaya kepemimpinan sebagai hubungan antara atasan dan bawahan yang saling mempengaruhi serta menimbulkan perubahan dan hasil pencapaian tujuan mereka. Definisi dari Robbins dan Judge (2013) memandangnya sebagai kemampuan untuk mempengaruhi sekelompok orang tertentu agar mampu mencapai tujuan yang sudah ditetapkan. Kepemimpinan merupakan proses untuk mempengaruhi orang lain agar bisa memahami dan menyepakati apa yang harus dilakukan dan bagaimana cara melakukannya serta mendorong individu tersebut untuk mencapai sasaran bersama (Yukl, 2010). Penelitian ini menggunakan teori kepemimpinan path-goal yang dikenalkan Robert House (Robbins \& Judge, 2013). Teori ini menekankan bahwa atasan harus menyiapkan alur yang jelas dalam menjalankan pekerjaan. Pemimpin harus memberikan arahan dan dukungan atau sumberdaya lain yang bermanfaat bagi bawahan dalam menyelesaikan pekerjaan. Konsep ini juga berpandangan bahwa berbagai perilaku pemimpin dapat diterapkan dalam berbagai situasi dan waktu yang berbeda. Terdapat empatperilaku utama di dalam konsep path-goal; direktif, suportif, partisipatif, dan orientasi hasil (Daft, 2014). Gaya kepemimpinan yang diterapkan oleh pemimpin dapat menimbulkan berbagai akibat baik yang positif maupun yang negatif. Sisi positifnya adalah meningkatkan motivasi, kinerja, kepuasan kerja, dan komitmen karyawan. Sedangkan gaya yang tidak sesuai 
akan berdampak terhadap pada sikap kerja yang sama akan tetapi dengan arah berlawanan (negatif). Pemimpin diharapkan dapat menerapkan gaya yang sesuai dengan kondisi yang dihadapi serta selaras dengan tingkat pemahaman tim kerjanya.

\section{Motivasi Kerja}

Salah satu faktor pendorong bagi individu agar mampu menampilkan kinerja optimal adalah jika memiliki motivasi untuk melakukannya. Motivasi merupakan konsep yang digunakan untuk memahami perilaku yang diamati (Gibson dkk., 2012). Kita sebagai individu memahami perilaku orang lain didasarkan pada pengetahuan dan latar belakang yang kita miliki. Sebagai contoh, seorang individu bekerja lembur kita simpulkan bahwa yangbersangkutan sedang memerlukan penghasilan tambahan (motivasi finansial). Akan tetapi, pada kenyataannya, individu tersebut melakukannya dengan sukarela karena menikmati pekerjaan dalam proyek tersebut. Gibson dkk (2012) mendefinisikan motiasi sebagai suatu kekuatan yang mendorong atau mengarahkan individu untuk melakukan perilaku tertentu. Sebagian besr ahli berpendapat bahwa motivasi merupakan kekuatan yang timbul dari dalam diri individu dalam merespon kebutuhan atau tujuan yang hendak dicapai. Dalam kaitannya dengan dunia kerja, tentu tujuan tersebut adalah hasil kerja yang baik. Definisi lain dari Robbins dan Judge (2013) menyatakan motivasi sebagai suatu proses yang menjelaskan intensitas, arah, dan persistensi dari individu tertentu dalam mencapai tujuannya. Teori-teori tersebut banyak digunakan untuk memahami apa yang melatar belakangi individu melakukan suatu aktivitas. Motivasi merupakan salah satu perilaku individu (karyawan) yang penting karena memiliki hubungan dengan kinerja karyawan (Anuj \& Anita, 2015; Khan \& Gautam, 2014; Imanzadeh \& Gindugdu, 2011; Robescu \& Iancu, 2016; and Ibrahim \& Brobbey, 2015). Beragam teori motivasi dikembangkan diantaranya Teori Hirarki Kebutuhan dari Maslow, Teori X dan Y dari McGregor, Teori Dua Faktor dari Herzberg, Teori Kebutuhan McLelland, Teori Self-Determination, engagement, dan Goal Setting (Robbins \& Judge, 2013). Penelitian ini menggunakan konsep dasar Teori Kebutuhan yang dikembangkan oleh McLelland.

\section{Hubungan Gaya Kepemimpinan dan Motivasi Kerja}

Penelitian yang membahas kepemimpinan dan motivasi kerja sudah banyak dilakukan. Penelitian ini akan menambah keluasan pembahasan karena menggunakan responden dari industri yang berbeda (perbankan). Penelitian terdahulu yang membahas hubungan gaya kepemimpinan dan motivasi menunjukkan hasil yang beragam. Sebagian besar memperlihatkan temuan adanya pengaruh signifikan dan positif dari gaya kepemimpinan terhadap motivasi (Alasad, 2017; Eyal \& Roth, 2011; Rawung, 2013). Meski demikian, ada pula yang menemukan hubungan dengan arah yang berlawanan atau negatif (Mengesha, 2015; Gopal \& Chowdhury, 2014; Al-Haj, 2017). Penelitian lain memunculkan hasil yang benar-benar berbeda ketika memperlihatkan bahwa tidak ada hubungan signifikan antara kepemimpinan dan motivasi (Gooraki dkk., 2013; Alasad, 2017). Ditinjau dari gaya kepemimpinan, berdasarkan riset yang digunakan sebagai acuan, nampak bahwa gaya kepemimpinan transformasional paling sering digunakan sebagai variabel independen. Pengukuran tidak terbatas pada gaya kepemimpinan secara keseluruhan, akan tetapi banyak peneliti yang mengukur dimensi dari gaya kepemimpinan tersebut. Tabel 1 memperlihatkan rangkuman berbagai hasil penelitian mengenai gaya kepemimpinan dan motivasi kerja. Berdasarkan kajian literatur terdahulu, maka penelitian ini menentukan hipotesis sebagai berikut;

$\boldsymbol{H}_{1}$ : Gaya kepemimpinan memiliki pengaruh signifikan positif dengan motivasi kerja karyawan 
Tabel 1. Penelitian Terdahulu Mengenai Gaya Kepemimpinan \& Motivasi Kerja

\begin{tabular}{|c|c|c|c|c|c|}
\hline Peaulis \& Takan & Negara/Kota & Industri/Organisasi & Gas Kepenimpinan & Hasi Peselitian & $\mathbf{R}$ \\
\hline Afrizal 2015 & $\begin{array}{l}\text { Iodonocia } \\
\text { Yograciarta }\end{array}$ & $\begin{array}{l}\text { Lentage ketangan nen } \\
\text { bunk } 12 \text { responden }\end{array}$ & Path-goal & Positif & \\
\hline \multirow{3}{*}{ Al Haj, 2017} & \multirow{3}{*}{ Qant } & \multirow{3}{*}{ Publik sebor, 92 responden } & Transfirmaciomal & Pouitif & 06. \\
\hline & & & a Iransaksional & Posinif & 0.6 \\
\hline & & & Pastivy avodarce & Nequaf & 0 sen \\
\hline \multirow{5}{*}{ Alasad, 2017} & \multirow{5}{*}{ Isral } & \multirow{5}{*}{ Akacemil, 306 responden } & Transfirmasional & Poitif dan notivasi inrinsk & 0359 \\
\hline & & & Transfirmasional & Poitif den motivasi imrinste & 0.412 \\
\hline & & & Transaksconal & Tidak sigriflian & \\
\hline & & & Laisiez fare & Negatif dan motirasi iswinad. & 0.374 \\
\hline & & & taisters Faise & Negatif ian motriaci intrinal & 0174 \\
\hline \multirow{2}{*}{$\begin{array}{l}\text { Alphare \& A Al-Aari } \\
2015\end{array}$} & \multirow{2}{*}{ Aab Saud } & \multirow{2}{*}{ Petrikimin, 30 responden } & Transtrumasional & Positif & \\
\hline & & & Irassaksonal & Negant & \\
\hline Affradact al 20:3 & Qatur & Akadcmil, 459 responden & Díchaff & Positif & 0.315 \\
\hline Extengge et al, zols & $\begin{array}{l}\text { Iudonetin } \\
\text { Padang }\end{array}$ & $\begin{array}{c}\text { Kantor pemerintith } 68 \\
\text { tespoeden }\end{array}$ & Pattmaksol & Ponitif & 0.441 \\
\hline Goarabiet al 2013 & Irm, Shima & Kescriatas, 190 requonden & $\begin{array}{c}\text { Tidak disebutkan } \\
\text { Hasus }\end{array}$ & Tihak ada huhunģan & \\
\hline \multirow{2}{*}{$\begin{array}{l}\text { Gopal \& Chrowdury } \\
2014\end{array}$} & \multirow[b]{2}{*}{ Inta } & \multirow[b]{2}{*}{ Perminyalan :0 reiponten } & Transtormasional & Positif & 0.602 \\
\hline & & & $\begin{array}{l}\text { Irassaksonal } \\
\text { Laisiez Farre }\end{array}$ & $\begin{array}{l}\text { Positif } \\
\text { Nezzatif }\end{array}$ & $\begin{array}{l}0.327 \\
0.585 \\
\end{array}$ \\
\hline $\begin{array}{l}\text { Khrong \& Foant } \\
2015\end{array}$ & $\begin{array}{l}\text { Vietnim, } \\
\text { Saitun }\end{array}$ & Auditor, 320 respodes & Beragxn & Poitif & 0.803 \\
\hline \multirow{3}{*}{ Mergesia, 2015} & \multirow{3}{*}{ Ethicin } & \multirow{3}{*}{ Akacemil, 210 responden } & Transformasional & Positif & 0.621 \\
\hline & & & Iransaksocoal & Poiniff & 0.44 \\
\hline & & & Laisiez Faze & Negatif & 0.585 \\
\hline Ravung 2013 & $\begin{array}{l}\text { ladonesin, } \\
\text { Manado }\end{array}$ & Akademik, 55 respenden & 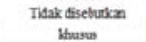 & Positif & 0.523 \\
\hline Syayid et al 2013 & $\begin{array}{l}\text { ladonesia } \\
\text { Maling }\end{array}$ & Media,, 22 responden & Path-goal & Positif & 0.91 \\
\hline
\end{tabular}

\section{METODOLOGI}

Sampel

Penelitian dilakukan di salah satu cabang utama Bank BNI di Bandung. Kuesioner disebarkan ke 100 orang karyawan dan diterima kembali sebanyak 75 orang (75\%). Tabel 2 menunjukkan komposisi responden secara detail dari berbagai faktor demografis.

Tabel 2. Aspek Demografis

\begin{tabular}{|c|c|c|c|c|}
\hline Demografis & Kriteria & Jumlah & Presentase & Total \\
\hline \multirow{2}{*}{ Jenis Kelamin } & Pria & 50 & $67 \%$ & \multirow{2}{*}{$100 \%$} \\
\hline & Wanita & 25 & $33 \%$ & \\
\hline \multirow{7}{*}{ Usia } & $<21$ tahun & 7 & $9 \%$ & \multirow{7}{*}{$100 \%$} \\
\hline & $>35-40$ tahun & 3 & $4 \%$ & \\
\hline & $>50$ tahun & 7 & $9 \%$ & \\
\hline & $21-30$ tahun & 36 & $48 \%$ & \\
\hline & $>40-45$ tahun & 20 & $27 \%$ & \\
\hline & $>30-35$ tahun & 1 & $1 \%$ & \\
\hline & $>40-50$ tahun & 1 & $1 \%$ & \\
\hline \multirow{3}{*}{ Status } & Menikah & 71 & $95 \%$ & \multirow{3}{*}{$100 \%$} \\
\hline & Belum Menikah & 4 & $5 \%$ & \\
\hline & Cerai & 0 & $0 \%$ & \\
\hline \multirow{5}{*}{ Lama Bekerja } & $<1$ tahun & 16 & $21 \%$ & \multirow{5}{*}{$100 \%$} \\
\hline & $>5-10$ tahun & 9 & $12 \%$ & \\
\hline & $1-3$ tahun & 0 & $0 \%$ & \\
\hline & $>10$ tahun & 26 & $35 \%$ & \\
\hline & $>3-5$ tahun & 24 & $32 \%$ & \\
\hline \multirow{3}{*}{ Posisi dalam Bekerja } & Non Jabatan (pelaksana, admin, officer) & 62 & $83 \%$ & \multirow{3}{*}{$100 \%$} \\
\hline & Manajer & 9 & $12 \%$ & \\
\hline & Supervisor & 4 & $5 \%$ & \\
\hline \multirow{4}{*}{ Status Karyawan } & Outsourcing & 55 & $73 \%$ & \multirow{4}{*}{$100 \%$} \\
\hline & Kontrak & 3 & $4 \%$ & \\
\hline & Trainee & 0 & $0 \%$ & \\
\hline & Karyawan Tetap & 17 & $23 \%$ & \\
\hline \multirow{5}{*}{ Pendidikan } & SMA/SMK & 44 & $59 \%$ & \multirow{5}{*}{$100 \%$} \\
\hline & Diploma & 8 & $11 \%$ & \\
\hline & S1 & 21 & $28 \%$ & \\
\hline & S2 & 1 & $1 \%$ & \\
\hline & S3 & 1 & $1 \%$ & \\
\hline
\end{tabular}

\section{Teknik Analisis}

Penelitian ini bertujuan mengukur hubungan dan pengaruh antar variabel. Hal tersebut dicapai dengan menggunakan teknik analisis regresi sederhana. Di samping itu, kajian deskriptif juga dilakukan untuk menentukan tingkatan persepsi karyawan terhadap gaya kepemimpinan yang diterapkan di organisasi dan tingkat motivasi kerja. Sesuai dengan persyaratan uji regresi sederhana, sebelum dilakukan analisis regresi, uji asumsi untuk mengetahui normalitas dan heterokedastisitas data dilakukan.

\section{Alat Ukur}

Kuesioner untuk penelitian ini terdiri dari 36 item pertanyaan. 18 item pertanyaan untuk gaya kepemimpinan yang diambil dari konsep Famakin \& Abisuga (2016). Salah satu pertanyaan yang diajukan adalah 'Pimpinan meminta anggota untuk mengikuti standar peraturan dan kebijakan.' Pertanyaan untuk motivasi kerja terdiri dari 18 buah yang dibangun dari konsep McLelland (Robbins \& Judge, 2015). Contoh pertanyaan yang diajukan 'Berusaha menjalankan pekerjaan lebih awal dari deadline yang diberikan'. Setiap pertanyaan memiliki 6 alternatif jawaban dengan pilihan; 6 (sangat setuju), 5 (setuju), 4 (ragu cenderung setuju), 3 (ragu cenderung tidak setuju), 2 (tidak setuju), dan 1 (sangat tidak setuju). Uji reliabilitas menggunakan Cronbach's Alpha memperlihatkan nilai internal 0.871 untuk gaya kepemimpinan dan 0.864 untuk motivasi.

\section{PEMBAHASAN dan HASIL}

Hasil penelitian mengungkapkan bahwa karyawan merasa sesuai dengan gaya kepemimpinan yang saat ini diterapkan di BNI KCU JPK Bandung. Hal ini nampak dari hasil perhitungan terhadap jawaban yang diberikan responden terkait pertanyaan kesesuaian gaya kepemimpinan dan hambatan karena penerapan gaya kepemimpinan tersebut. Dari nilai maksimal 6 poin, rata-rata untuk jawaban tersebut diperoleh angka 5.69 yang tergolong sangat tinggi. Dalam pengertian penerimaan karyawan atas gaya kepemimpinan atasan maka nilai tersebut diartikan sebagai sangat sesuai. Sedangkan untuk dimensi gaya kepemimpinan path-goal, dimensi tertinggi adalah orientasi pada prestasi (5.66), diikuti oleh gaya berorientasi partisipatif (5.54), orientasi direktif (5.4) dan orientasi suportif (5.15). Nilai yang relatif berimbang tersebut mencirikan bahwa pemimpin pada organisasi tersebut berhasil menerapkan 
beragam gaya kepemimpinan yang sesuai dengan kondisi dan situasi yang dihadapi. Hal ini didukung dengan kondisi kerja yang nyaman dimana karyawan dapat berinteraksi secara optimal dengan atasannya. Tidak ada kendala komunikasi dalam berinteraksi. Di samping itu, karyawan juga relatif bebas menyampaikan pandangannya. Di sisi lain, atasan tidak menjaga jarak dalam berinteraksi serta dinilai mampu memberikan masukan, panduan, dan arahan yag jelas terkait pekerjaan yagn harus dilakukan. Hal-hal positif ini tidak heran menyebabkan tingkat motivasi karyawan juga berada pada kategori sangat tinggi (5.7 dari nilai tertinggi 6). Selanjutnya penelitian ini akan menjawab hipotesis yang ditetapkan sebelumnya terkait hubungan pengaruh gaya kepemimpinan terhadap motivasi kerja. Untuk menjelaskan ada atau tidaknya hubungan pengaruh tersebut, digunakan analisis regresi sederhana. Sebelum melakukan analisis regresi perlu dilakukan uji asumsi klasik untuk memastikan bahwa data dapat digunakan. Untuk regresi sederhana uji asumsi kalsik dilakukan untuk melihat normalitas data dan heterokedastisitas. Uji normalitas dilakukan menggunakan metode uji one sample Kolmogorov Smirnov sedangkan uji heterkedastisitas menggunakan uji koefisien korelasi Spearman's Rho. Tabel 3 dan 4 memperlihatkan hasil uji asumsi klasik tersebut

Tabel 3. Uji Normalitas

\begin{tabular}{lr} 
& \multicolumn{2}{c}{ Unstandardized } \\
& Residual \\
\hline $\mathrm{N}$ & 75 \\
Kolmogorov-Smirnov Z & 1.307 \\
Asymp. Sig. (2-tailed) & $\mathbf{. 0 6 6}$ \\
\hline
\end{tabular}

Tabel 4. Uji Heterekodastisitas

\begin{tabular}{crr}
\hline & $\begin{array}{c}\text { LEADER } \\
\text { STYLE }\end{array}$ & $\begin{array}{c}\text { Unstandardized } \\
\text { Residual }\end{array}$ \\
\hline Spearman LEADER Correlation & & -.041 \\
Coefficient & 1.000 & $\mathbf{7 2 8}$ \\
Sig. (2-tailed) & & 75 \\
$\mathrm{~N}$ & 75 & \\
\hline
\end{tabular}

Setelah lolos uji asumsi klasik, maka langkah berikut adalah melakukan analisis regresi sederhana menggunakan aplikasi SPSS. Tabel 5 menunjukkan hasil korelasi antara gaya kepemimpinan dan motivasi kerja sebesar 0.633.
Angka ini mencerminkan hubungan yang tergolong kuat (Neolaka, 2014).

Table 5. Korelasi

\begin{tabular}{llrr}
\hline & & MOTIVATION & LEADERSTYLE \\
\hline Pearson & MOTIVATION & 1.000 & $\mathbf{. 6 3 3}$ \\
Correlation & LEADERSTYLE & .633 & 1.000 \\
Sig. (1- & MOTIVATION & & $\mathbf{. 0 0 0}$ \\
tailed) & LEADERSTYLE & .000 & \\
\hline
\end{tabular}

Tabel 6 dan 7 memperlihatkan bahwa gaya kepemimpinan memiliki pengaruh signifikan positif terhadap motivasi kerja (nilai signifikansi $p<0.05)$. Motivasi kerja karyawan di BNI KCU JPK, Bandung dapat dijelaskan oleh gaya kepemimpinan sebesar $40.1 \%$.

Tabel 6. Model Summary

Adjusted Std. Error of Model R R Square R Square the Estimate \begin{tabular}{lllll}
\hline 1 & $633^{\mathrm{a}}$ & .401 & .393 & .27271 \\
\hline
\end{tabular}

Table 7. Annova

\begin{tabular}{|c|c|c|c|c|c|c|}
\hline Model & & $\begin{array}{c}\text { Sum of } \\
\text { Squares }\end{array}$ & $\mathrm{df}$ & $\begin{array}{c}\text { Mean } \\
\text { Square }\end{array}$ & $\mathrm{F}$ & Sig. \\
\hline \multirow[t]{3}{*}{1} & $\begin{array}{l}\text { Regressi } \\
\text { on }\end{array}$ & 3.632 & 1 & 3.632 & 48.831 &, $000^{\mathrm{b}}$ \\
\hline & Residual & 5.429 & 73 & .074 & & \\
\hline & Total & 9.061 & 74 & & & \\
\hline
\end{tabular}

Hasil tersebut menjawab hipotesis penelitian ini yang menerima $\mathrm{H}_{1}$ dan sekaligus menguatkan hasil penelitian terdahulu yang menyatakan adanya hubungan signifikan positif antara gaya kepemimpinan dan motivasi kerja. Penelitian di Yogyakarta dan Malang memiliki hasil yang sama (Afrizal, 2015 \& Syaiyid dkk., 2013). AlSada di Qatar juga menemukan bahwa pemimpin yang mengelola tim dengan orientasi direktif memiliki hubungan positif dengan motivasi karyawan. Angka korelasi hasil penelitian ini sebesar 0.633 yang merupakan angka terbesar kedua jika dibandingkan dari penelitian terdahulu. Korelasi terbesar diperoleh penelitian Khuong dan Hoang (2015) di Vietnam sebesar 0.803. Manajemen sebaiknya mempertahankan gaya kepemimpinan yang saat ini diterapkan karena dinilai memiliki manfaat positif untuk membangun motivasi kerja karyawan. Perilaku pemimpin dalam mengelola tim kerjanya mencakup berbagai tanggung jawab diantaranya 
adalah membangun kepercayaan, kerjasama tim, memberikan inspirasi, dorongan, serta mengembangkan bawahannya. Meski tujuan utama pemimpin adalah mencapai sasaran yang ditetapkan perusahaan, akan tetapi dalam upaya mencapainya, pemimpin perlu menggerakkan tim kerjanya. Teknik komunikasi dan hubungan interpersonal yang baik akan melengkapi ketrampilan pemimpin dalam mengarahkan timnya. Karyawan yang memiliki persepsi positif terhadap pimpinannya; merasa diperhatikan, dianggap berkontribusi, diterima ide-idenya, memberi inspirasi, merasa didukung akan menjadi lebih termotivasi dalam menjalankan pekerjaan. Penelitian ini menemukan fakta bahwa gaya kepemimpinan yang tepat dapat meningkatkan motivasi karyawan. Karyawan yang termotivasi ini nantinya akan berkontribusi bagi perusahaan. Perilaku pemimpin yang diterima oleh tim kerjanya membuat karyawan merasa tidak terbebani dalam bekerja. Mereka tidak bekerja dibawah tekanan sehingga relatif mudah berkreasi dan berprestasi. Keragaman gaya kepemimpinan yang diterapkan di perusahaan yang diteliti menggambarkan kemampuan pemimpin yang baik dalam mengantisipasi dan beradaptasi pada kondisi yang beragam. Ke empat dimensi kepemimpinan path-goal, tercermin dengan seimbang. Gaya direktif diperlukan ketika organisasi menentukan sasaran yang harus dicapai dan bagaimana cara mencapainya. Penentuan target tahunan diberikan oleh kantor pusat dan diturunkan ke bawah oleh pimpinan cabang. Gaya partisipatif dan suportif diterapkan ketika dalam proses pelaksanaan pekerjaan bawahan mengalami kendala. Pimpinan ideal akan memberikan dukungan (memberikan alternatif solusi, memberikan pembekalan) serta aktif berpartisipasi dalam kegiatan operasional. Hal ini dilakukan bukan didasarkan pada ketidakpercayaan, akan tetapi lebih pada bentuk perhatian sekaligus memantau kendala yang dihadapi. Terakhir, pemimpin tentu senantiasa memantau perkembangan pencapaian target. Di industri perbankan, ini tentu dilakukan secara rutin baik harian, mingguan, atau bulanan. Pemimpin cabang mendapat target jumlah uang yang diterima dan disalurkan serta kepuasan pelanggan. Setelah target ditetapkan, pemimpin memiliki kendali penuh atas strategi yang digunakan untuk mencapai target. Evaluasi dan pertemuan rutin dilakukan untuk melihat perkembangan pencapaian target. Apabila target tercapai, maka pemimpin hanya perlu 6 menegaskan kepada karyawan untuk tetap menjaga konsistensi. Akan tetapi jika ada kendala dimana target belum tercapai, maka identifikasi awal bisa membantu mereka untuk melakukan langkah perbaikan. Secara singkat dapat diperoleh gambaran mengenai pentingnya kontribusi gaya kepemiminan yang diterapkan dengan tingkat motivasi karyawan. Gaya kepemimpinan menjadi landasan penting dalam keberhasilan perusahaan. Pemimpin yang baik akan membangun ikatan positif dengan tim kerjanya sehingga bisa terjalin komunikasi terbuka dua arah. Komunikasi yang lancar dan tidak ada kendala bermanfaat ketika ada masalah yang harus segera diselesaikan. Pemimpin yang baik juga mampu menentukan target yang harus dicapai bawahannya. target harus jelas dan bisa diukur serta memiliki cakupan waktu yang jelas pula. Selanjutnya, pemimpin ideal juga bisa memberikan arahan bagaimana cara mencapai target tersebut. Jadi tidak sekedar menentukan sasaran, akan tetapi mereka memiliki cara ideal untuk mencapainya. Komunikasi dan hubunan interpersonal yang baik diperlukan ketika ada masalah yang harus diselesaikan. Ide atau masukan dari bawahan akan mengalir lancar apabila pemimpin mau membuka diri bagi masukan dari bawah. Seringkali masukan dari bawahan yang dinilai sederhana ternyata malah menjadi solusi yang tepat bagi masalah yang dihadapi. Kontribusi pemimpin dalam menggerakkan bawahan untuk mencapai sasaran organisasi sagat besar. Tidak ada salahnya organisasi mulai melakukan upaya konkrit untuk meningkatkan kemampuan para pemimpinnya dalam memotivasi karyawan agar mampu lebih berkontribusi.

\section{KESIMPULAN}

Tingkat motivasi karyawan BNI KCP JPK Bandung berada pada kategori sangat tinggi, demikian pula dengan persepsi karyawan terhadap gaya kepemimpinan yang diterapkan juga sangat sesuai. Peran pemimpin untuk membangun motivasi karyawan sangat penting. Pemimpin dapat menyentuh hati dan pikiran karyawan dengan cara memberikan arahan yang jelas, panduan yang tepat, serta contoh nyata dalam kegiatan sehari-hari. Salah satu langkah mudah yang bisa dilakukan adalah dengan membuka jalur komunikasi dua arah. Melalui model yang terbuka dan mengikis jarak, karyawan atau bawahan lebih mudah dalam menyampaikan aspirasinya. Dalam kondisi tertentu memang diperlukan pemimpin yang 
tidak terlalu banyak bertanya, akan tetapi langsung mengambil keputusan yang penting. Hal yang perlu diingat adalah pengambilan keputusan tersebut bertujuan untuk mencapai kepentingan yang lebih besar, bukan berdasarkan kepentingan pribadi. Nilai-nilai positif yang dibangun oleh para pemimpin diharapkan dapat lebih meningkatkan motivasi kerja karyawan. Mereka bekerja lebih baik karena yakin bahwa pemimpin mereka juga melakukan hal yang sama. Peran pemimpin sebagai motivator harus dipertahankan, bahkan ditingkatkan. Sesuai dengan hasil penelitian yang ada, peran pemimpin sangat vital untuk keberhasilan perusahaan. Perilaku dan keputusan yang mereka ambil dapat memudahkan, mendorong, menyemangati karyawan. Pemimpin harus memiliki sikap yang kuat berdasarkan asas kepentingan yang lebih besar. Hanya dengan kepribadian dan gaya kepemimpinan yang konsisten dinilai positif oleh karyawan, maka seorang pemimpin juga akan berhasil menjadi motivator yang unggul bagi karyawannya. Pada akhirnya tingginya tingkat motivasi ini akan terbayar dalam bentuk pencapaian target dan peningkatan kinerja organisasi.

\section{REFERENSI}

Afrizal, A. (2015). Pengaruh Gaya Kepemimpinan Terhadap Motivasi Kerja Dan Kepuasan Kerja Serta Dampak Pada Kinerja Karyawan (Studi Kasus BMT Bina Ihsanul Fikri Yogyakarta) - Jurnal Ekonomi Syariah Indonesia, Volume V, No. 2, 151-170.

Akhtar, N., Aziz, S., Hussain, Z., Ali, S., \& Salman, M. (2014). Factors Affecting Employees Motivation in Banking Sector of Pakistan. Journal of Asian Business Strategy, Vol. 4, No. 10, 125133.

Al Haj, A. (2017). Leadership Styles and Employee Motivation in Qatar Organizations. Walden Dissertations and Doctoral Studies. Walden University.

Alasad, S. (2017). The Leadership Styles of Principals in Bedouin Secondary School and Teachers Motivation. Philosophy Study, Vol. 7, No. 3, 153-168.

Alghazo, A.M. \& Al-Anazi, M. (2016). The Impact of Leadership Style on Employee's Motivation - International Journal of Economics and Business Administration Vol. 2, No. 5, 37-44.
Al-Sada, M., Al-Esmael, B., \& Faisal, M.N. (2017). Influence of organizational culture and leadership style on employee satisfaction, commitment and motivation in the educational sector in Qatar. EuroMed Journal of Business, Vol. 12 Issue: 2, pp.163-188.

Anthony, R. (2017). 7 Indicators Of High Employee Motivation. https://www.linkedin.com/pulse/7indicators-high-employee-motivationray-anthony/. Diakses 18 Desember, 2017.

Anuj, S. \& Anita, S. (2015). Impact of Motivation on Employee's Performance / Productivity. International Journal of Scientific Research and Reviews, Vol. 4, No. 1, 81-87.

Barone, R. (2016). The Importance of Motivation and Its Role in the Workplace. https://www.xactlycorp. com/blog/importance-motivation-roleworkplace/. Diakses 18 Desember, 2017.

Blasingame, J. (2015). Motivating Employees Is Good Business. https://www.forbes. com/sites/jimblasingame $/ 2015 / 08 / 07 / \mathrm{mo}$ tivating-employees-is-good-business /\#2ef955d15ab0. Diakses 19 Desember, 2017.

Daft, R. (2005). The Leadership Experience, 6th Edition, USA: Cengage Learning.

Daum, K. (2015). 17 Ways Great Leaders Motivate Their People. https://www.inc. $\mathrm{com} /$ kevin-daum/17-ways-great-leaders motivate-their- people.html. Diakses 16 Desember, 2017.

Decaro, N. E. (2005). An investigation of the relationship of initiating structure, consideration and gender perception: an examination of the path-goal theory, UMI No. 3187623, Doctoral Dissertation, ProQuest Dissertations and theses database.

Erlangga, F., Frinaldi, A., \& Magriasti, L. (2013). Pengaruh Gaya Kepemimpinan Paternalistik Terhadap Motivasi Kerja Pegawai Dinas Sosial dan Tenaga KerjaKota Padang. HUMANUS, 12(2), 174-195.

Eyal, O. \& Roth, G. (2011). Principals' leadership and teachers' motivation: Self-determination theory analysis. Journal of Educational Administration, Vol. 49 Issue: 3, pp.256-275. 
Famakin, I.O., \& Abisuga, A.O. (2016). Effect of Path-Goal Leadership Styles on The Commitment of Employees on Construction Project. International Journal of Construction Management, 16(1), 1-10.

Gooraki, E., Noroozi, H., Marhamati, S., \& Behzadi, F. (2013). The Effect of Leadership Style on The Employees' Job Motivation in Health Care Centers in Shiraz. Journal of Advances in Medical Education \& Professionalism, Vol. 1, No. 2, 59-63.

Gopal, R. \& Chowdhury, R. G. (2014). Leadership Styles And EmployeeMotivation: An Empirical Investigation In A Leading Oil Company In India - International Journal of Research in Business Management Vol.2, Issue 5, May 2014, 1-10.

Ibrahim, M. \& Brobbey, V.A. (2015). Impact of Motivation on Employee Performance The Case of Some Selected Micro Finance Companies in Ghana. International Journal of Economics, Commerce and Management, Vol. III, Issue 11, 1218-1236.

Imanzadeh, M., \& Gundogdu, C. (2011). Effect of motivation on employee performance of commercial banks in Kenya: A case study of Kenya Commercial Bank in Migori County. International Journal of Human Resource Studies. 7(3), 257-259.

Khan, A., Ahmed, S., Paul, S., \& Kazmi, S.H.A. (2017). Factors Affecting Employee Motivation Towards Employee Performance: A Study on Banking Industry of Pakistan. In $\mathrm{J}$. $\mathrm{Xu}$ et al. (eds.), Proceedings of the Eleventh International Conference on Management Science and Engineering Management, Lecture Notes on Multidisciplinary Industrial Engineering, 615-625.

Khan, M.S. \& Gautam, S. (2014). A Study of Impact of Motivation on Productivity of Employee. The International Journal of Business \& Management, Vol. 2, No. 12, 289-291.

Khuong, M.N., \& Hoang, D.T. (2015). The Effects of Leadership Styles on Employee Motivation in Auditing Companies in Ho Chi Minh City, Vietnam. International Journal of Trade,
Economics and Finance. Vol. 6, No. 4, 210-217.

Kusuma, H. Y., Susilo, H. \& Nurtjahjono, G. E. (2015). Pengaruh Insentif Terhadap Motivasi dan Kinerja (Studi pada KaryawanHotel Grand Pujon View Kabupaten Malang). Jurnal Administrasi Bisnis (JAB) Vol. 23 No. 1, 1-7.

Mengesha, A. H. (2015). Impact of leadership approaches on employee motivation: An empirical investigation in Haramaya University. AshEse Journal of Business Management, Vol. 1 (3), 028-038.

Naile, I., \& Selesho, J. M. (2014). The Role Leadership in Employee Motivation. Mediterranean Journal of Social Sciences, Vol. 5, No. 3, 175-182.

Neolaka, A. (2014). Metode Penelitian dan Statistik (1st ed). Bandung : PT Remaja Rosdakarya.

Osakwe, R. N. (2014). Factors Affecting Motivation and Job Satisfaction of Academic Staff of Universities in SouthSouth Geopolitical Zone in Nigeria. International Education Studies; Vol. 7,No. 7, 43-51.

Pilcher, J. (2017). Banking Leaders Must Become Champions for Change. https://thefinancialbrand.com/53547/cha nge-management-leadership-strategies/. Diakses 16 Desember, 2017.

Prakoso, R. D., Astuti, E. S. \& Ruhana, I. (2014). PengaruhLingkungan Kerja Terhadap Motivasi Kerja dan Kinerja Karyawan (Studi Pada Karyawan PT. AXA Financial Indonesia Cabang Malang). JurnalAdministrasi Bisnis (JAB), Vol. 14 No. 2, 1-10.

Rawung, F. H. (2013). The Effect of Leadership on the Work Motivation of Higher Education Administration Employees (Study at Manado State University). IOSR Journal of Business and Management (IOSR-JBM), Vol. 15, Issue 1, 28-33.

Robbins, S. P., \& Judge, T. A. (2013). Organizational Behavior, $15^{\text {th }}$ edition. New Jersey: Pearson Education Inc.

Robescu, O. \& Iancu, A. G. (2016). The Effects of Motivation on Employees Performance in Organizations. Valahian Journal of Economic Studies Volume 7 (21), Issue 2, 49-56.

Skinner, C. (2017). The Biggest Banking Challenge is Leadership. 
https://thefinanser.com/2015/01/the-

biggest-banking-is-leadership.html/.

Diakses 17 Desember, 2017.

Syaiyid, E., Utami, H. N., \& Riza, M.F. (2013). Pengaruh Gaya Kepemimpinan Terhadap Motivasi Kerja (Studi Pada Karyawan Radar Malang PT. Malang Intermedia Pers). Jurnal Administrasi Bisnis (JAB) Vol. 1 No. 1, 104-113.

Wulansari, P., Damanik, A. H., \& Prasetio, A. P. (2014). Pengaruh Kompensasi Terhadap Motivasi Karyawan di Departemen Sumberdaya Manusia PLN Kantor Distribusi Jawa Barat dan Banten. Jurnal Manajemen Indonesia, Vol. 14, No. 2, 164-170.

Yukl, G. (2010). Leadership in Organizations, 7th edition, Prentice Hall: New Jersey.

Zwilling, M. (2012). 8 Ways Leaders Can Motivate Employees Beyond Money. https://www.forbes.com/sites/martinzwilli ng/2012/01/10/8-ways-leaders-canmotivate-employees-beyondmoney/\#7be55e2a26f4. Diakses 17 
Volume 18, Nomor 1, November 2018, pp 1-10. Copyright (C) 2018 Jurnal Manajemen Maranatha, Program Studi S1-Manajemen, Fakultas Ekonomi, Universitas Kristen Maranatha. ISSN 1411-9293 | e-ISSN 2579-4094.

http://journal.maranatha.edu/jmm 